COUTO-VÁZQUEZ, A., GONZÁLEZ-PRIETO, S.J. (2006). Short- and medium- term effects of three fire fighting chemicals on the properties of a burnt soil. The Science of Total Environment 371, 353-361.

\title{
Short- and medium- term effects of three fire fighting chemicals on the properties of a burnt soil
}

\author{
Couto-Vázquez, A. and González-Prieto, S.J. ${ }^{1}$ \\ Instituto de Investigaciones Agrobiológicas de Galicia, CSIC. Apartado 122. \\ E-15780 Santiago de Compostela, Spain.
}

\begin{abstract}
The impact of three fire fighting chemicals (FFC) on 11 chemical soil properties and on soil recovery (0-2 cm depth) was evaluated 1, 30, 90 and $365 \mathrm{~d}$ after a prescribed fire. Five treatments were considered: unburnt soil (US) and burnt soil with $21 \mathrm{~m}^{-2}$ of water alone (BS) or mixed with the foaming agent Auxquímica RFC-88 at 1\% (BS+Fo), Firesorb at 1.5\% (BS+Fi) and FR Cross ammonium polyphosphate at $20 \%(B S+A p)$. At $t=1 \mathrm{~d}$, soil $\mathrm{pH}$ increases in the order US $<\mathrm{BS} \approx$ $\mathrm{BS}+\mathrm{Fo}, \mathrm{BS}+\mathrm{Fi}<\mathrm{BS}+\mathrm{Ap}$, which was most likely due to the accumulation of ashes, the reduction of organic acids and the cations supplied by FFC. In all burnt treatments, soil $\mathrm{pH}$ remained significantly higher than in US up until $\mathrm{t}=90 \mathrm{~d}$. SOM richness remained similar and constant until $t=90 \mathrm{~d}$ in all plots, but, probably due to fire-triggered erosion, at $\mathrm{t}=365 \mathrm{~d}$ it was significantly lower in BS+Ap (C, N), BS and BS+Fo (C) than in US. Immediately after the fire, soil $\delta{ }^{15} \mathrm{~N}$ decreased in all burnt soils (significatively in BS+Ap) due to the inputs of ${ }^{15} \mathrm{~N}$ depleted ashes from leguminous vegetation. Compared with US, soil $\delta{ }^{15} \mathrm{~N}$ increased significantly in all burnt plots between $t=90 \mathrm{~d}(30 \mathrm{~d}$ in BS+Ap) and $t=365 \mathrm{~d}$, suggesting a medium-term fire-triggered increment of $\mathrm{N}$ outputs $\left({ }^{15} \mathrm{~N}\right.$ depleted). As is habitually the case, there was a transient post-fire increase of $\mathrm{NH}_{4}^{+}-\mathrm{N}$ levels (significative for BS+FFC plots) that lasted for 30 (BS, BS+Fo and $\mathrm{BS}+\mathrm{Fi}$ ) to $90 \mathrm{~d}$ (BS+Ap). The high initial $\mathrm{NH}_{4}{ }^{+} \mathrm{N}$ levels in BS+Ap (200x that of US; 9-18x those of $\mathrm{BS}, \mathrm{BS}+\mathrm{Fo}$ and $\mathrm{BS}+\mathrm{Fi}$ ), and its persistence can delay the post-fire vegetation recovery due to the toxicity of $\mathrm{NH}_{4}^{+}$to seeds and seedlings. $\mathrm{NO}_{3}-\mathrm{N}$ levels changed significantly only in BS+Ap between $\mathrm{t}=30$ and $\mathrm{t}=90 \mathrm{~d}$ due to the nitrification of its large $\mathrm{NH}_{4}{ }^{+}-\mathrm{N}$ pool. Except in $\mathrm{BS}+\mathrm{Ap}$, whose soil P levels were 70-140x ( $\mathrm{t}=1 \mathrm{~d})$ and 10-20x ( $\mathrm{t}=365 \mathrm{~d})$ higher than in the other treatments, available $\mathrm{P}$ content in BS and BS+FFC was not significatively higher than in US. The concentrations of available cations in BS and BS+FFC were higher (not always significatively, except for K) than in US until $t=90 \mathrm{~d}$, likely due to ashes- and FFC-derived cations. Contrarily to divalent cations, monovalent cations (more soluble and easily leached) decreased slowly until $\mathrm{t}=90 \mathrm{~d}$.
\end{abstract}

Key words: Available nutrients; burnt soil; fire fighting chemicals; flame retardants; $\delta{ }^{15} \mathrm{~N}$; prescribed fire; wildfire.

\footnotetext{
${ }^{1}$ Author for correspondence.
} 


\section{Introduction}

Wildfires, which frequently degrade ecosystems from their base (the soil) by increasing nutrient and soil losses through leaching and erosion (Chandler et al., 1983; Carballas et al., 1993), are one of the most widespread factors of ecosystem degradation around the world; consequently, the improvement of wildfire fighting techniques is a global concern. The addition of substances to water to increase its effectiveness as a forest fire extinguishing agent has been a common practice since the beginning of the 1930s (Giménez et al., 2004). Studies on these substances, generically called fire fighting chemicals, have been traditionally focussed on the evaluation of their effectiveness as fire extinguishers when mixed with water, usually under laboratory conditions, although there are also field experiments (see reviews by George et al., 1976, and Giménez et al., 2004). Since most fire-fighting chemicals are typically applied in environmentally sensitive areas, natural areas and areas set aside for wildlife, there is a need to determine their potential effects on terrestrial and aquatic ecosystems (Basanta et al., 2002). There is a great deal of information regarding the effects of fire-fighting chemicals on plants and animals, both aquatic and terrestrial (Larson and Duncan, 1982; Bradstock et al., 1987; Gaikowski et al., 1996; MacDonald et al., 1996, 1997; Adams and Simmons, 1999; Larson et al., 2000; Giménez et al., 2004; Hartskeerl, et al., 2004; Bell et al., 2005). Conversely, in spite of its interest, the effects of these compounds on the soil have scarcely been studied (see Giménez et al., 2004). However, since the beginning of 1980s there has been concern regarding the possible consequences of $\mathrm{N}$ and $\mathrm{P}$ enrichment due to fire fighting chemicals application in ecosystems usually poor in these nutrients (Neary and Currier, 1982). More recently, Basanta et al. (2002) studied under laboratory conditions the effects of a fire fighting chemical over some biochemical properties of two heated and two unheated soils, whereas Hopmans and Bickford (2003) studied, for the period of one year under field conditions, the impact of another fire-fighting compound on the chemical properties of two unburnt soils. The last two studies focussed on two scenarios, unburnt and burnt soils plus retardant unaffected by the high temperatures associated with wildfire, probably due to the difficulties for studying the third possible scenario: soils in the fire line that receive retardant, and which are affected by both the heating and oxidation caused by the fire. On the other hand, the ratios of stable nitrogen isotopes expressed as $\delta{ }^{15} \mathrm{~N}$ values can indicate the openness of nitrogen cycles in ecosystems, and they are useful tools in evaluating the characteristics of $\mathrm{N}$ transformation in an ecosystem, as well as the past and current N status of forested ecosystems (Garten, 1993; Garten and Van Miegroet, 1995; Hogberg, 1991; Hogberg and Johannisson, 1993; Cook, 2001; Robinson, 2001; Koba et al. 2003). Moreover, soil isotopic signatures have been previously used to infer patterns of fire history (Schmidt and Stewart, 2003; Aranibar et al., 2003).

The aim of this paper is to evaluate, under field conditions, the impact of three fire fighting chemicals (foaming agent RFC-88 from Auxquímica, terpolymer Firesorb from Stockhausen and ammonium polyphosphate FR from Cross), applied immediately after a prescribed fire (i.e. with the fire extinguished but with the soil still warm), on 11 chemical properties of a forest soil in order to determine their effects on the post-fire recovery of the soil.

\section{Material and methods}

The experimental field, with UTM coordinates $29 \mathrm{~T}^{05} 182-{ }^{46} 509$, is located at Alto da Pedrada (Tomiño, Galicia, NW Spain) at an altitude of $455 \mathrm{~m}$ a.s.l. The soil, developed over a parent material of paragneises and with a slope of $18-19 \%$, has a vegetation cover dominated by Ulex, Chamaespartium and Erica 50-60 cm heigh.

Five treatments were considered: a) unburnt soil (US) as a control; b) burnt soil with $21 \mathrm{~m}^{-2}$ of water (BS); c) burnt soil with $21 \mathrm{~m}^{-2}$ of water plus foaming agent Auxquímica RFC-88 at 1\% 
(BS+Fo); d) burnt soil with $21 \mathrm{~m}^{-2}$ of water plus Firesorb at 1.5\%(BS+Fi); and e) burnt soil with $21 \mathrm{~m}^{-2}$ of water plus FR Cross ammonium polyphosphate at $20 \%$ (BS+Ap). After a prescribed fire (i.e. with the fire extinguished but with the soil still warm), burnt soil treatments were arranged in a fully randomized design with four replications and $1 \mathrm{~m}$ separation around each plot $(4 \times 4$ $\mathrm{m}$ ), whereas the four unburnt soil replicates were established along the slope and adjacent to the burnt ones (see Fig. 1).

Soil samples were taken from the A horizon (0-2 cm depth) immediately before and after burning and 1, 3 and 12 months after the prescribed fire. Five $15 \times 15 \mathrm{~cm}$ squares, uniformly distributed around each plot, were sampled, mixed and thoroughly homogenized after sieving at $4 \mathrm{~mm}$. Before the prescribed fire, plant litter was also sampled in all plots, dried at $60^{\circ} \mathrm{C}$, finely ground $(<100 \mu \mathrm{m})$ and kept for analysis.

The dry matter content of fresh soils and litter was assessed by oven-drying aliquots of them at $110{ }^{\circ} \mathrm{C}$ for $5 \mathrm{~h}$. Soil $\mathrm{pH}$ was measured with a $\mathrm{pH}$-meter (Metröhm, Switzerland) in $0.1 \mathrm{M} \mathrm{KCl}$ employing a soil: solution ratio of 1:2.5.

Available $\mathrm{Na}, \mathrm{K}, \mathrm{Ca}, \mathrm{Mg}$ and $\mathrm{P}$ were extracted with acetic acid $0.5 \mathrm{M}$ (soil:extractant ratio 1:40). All available nutrients were measured by inductively coupled plasma optical emission spectrometry (Varian Vista Pro simultaneous ICP-OES).

The $\mathrm{C}$ and $\mathrm{N}$ contents of soils and litter, as well as their $\delta^{15} \mathrm{~N}$ values, were measured on finely ground samples $(<100 \mu \mathrm{m})$ with an elemental analyzer (EA) coupled on-line with an isotopic ratio mass spectrometer (Finnigan Mat, delta C, Bremen, Germany).

For the inorganic $\mathrm{N}$ analysis $\left(\mathrm{NH}_{4}{ }^{+}\right.$and $\left.\mathrm{NO}_{3}{ }^{-}\right)$an extraction-diffusion method, at room temperature, was used. Fresh soil samples $(20 \mathrm{~g})$, in duplicate, were shaken with $100 \mathrm{ml}$ of $2 \mathrm{M}$ $\mathrm{KCl}$ for $1 \mathrm{~h}$ and the extracts were filtered through glass microfibre filters (Whatman GF/ A, 125 mm diameter). In order to sequentially liberate $\mathrm{NH}_{4}-\mathrm{N}$ and $\mathrm{NO}_{2}+\mathrm{NO}_{3}-\mathrm{N}$ in the form of $\mathrm{NH}_{3}$ $25 \mathrm{ml}$ aliquots of $2 \mathrm{M} \mathrm{KCl}$ soil extracts, placed in a $500 \mathrm{ml}$ wide-mouth glass jar, were treated successively ( $5 \mathrm{~d}$ periods) with $\mathrm{MgO}$ and $\mathrm{MgO}$ plus Devarda's alloy. Gaseous $\mathrm{NH}_{3}$ was trapped in $10 \mathrm{ml}$ of $0.005 \mathrm{M} \mathrm{H}_{2} \mathrm{SO}_{4}$ in a Teflon bottle attached to the glass jar and measured by back titration of the excess of $\mathrm{H}_{2} \mathrm{SO}_{4}$ with $0.01 \mathrm{M} \mathrm{NaOH}$.

The nutrient content of the fire fighting agents, measured by ICP-OES ( $\mathrm{Na}, \mathrm{K}, \mathrm{Ca}, \mathrm{Mg}$ and $\mathrm{P}$ ) and AE-IRMS $\left(\mathrm{N}, \delta{ }^{15} \mathrm{~N}\right)$, as well as their densities are shown in Table 1.

Data of soil variables analysed at several dates after the fire were statistically analysed by two-way ANOVA (with treatment and sampling time as factors) and the Levene's test was used for verifying the equality of variances among groups. In the case of homocedasticity, significant differences among the mean groups were established at $P<0.05$ using the Bonferroni test for multiple comparisons. In the case of unequal variances, the original data were subjected to CoxBox transformations to obtain equality of variances, and significant differences among the mean groups were then established at $P<0.05$ using the Bonferroni test for multiple comparisons.

\section{Results}

Before the prescribed fire there were no significative differences among the plots assigned to the different treatments for any of the variables studied, which shows acceptable spatial homogeneity of the experimental field.

Compared with that of the unburnt soil $\left(\mathrm{pH}_{\mathrm{KCl}} 3,36\right)$, the $\mathrm{pH}_{\mathrm{KCl}}$ of the burnt soil was 0.4 units higher $(P<0.05)$, and those of the burnt soil with fire fighting chemicals were 0.5 (BS+Fo and $\mathrm{BS}+\mathrm{Fi} ; P<0.05)$ to 0.9 units (BS+Ap) higher, the $\mathrm{pH}_{\mathrm{KCl}}$ in the latter being significantly higher $(P$ $<0.05$ ) than in US and BS (Fig. 2). In the burnt soils, with or without fire fighting chemicals, the 
$\mathrm{pH}$ remained significantly higher than in the US for at least three months after the prescribed fire, although there was a clear decreasing tendency in BS+Ap during this period. One year after the fire the burnt soils $\mathrm{pH}$ decreased to values close to US; the same was true for the burnt soils treated with fire fighting chemicals.

The SOM richness in the different plots remained similar and constant (total C: $149-207 \mathrm{~g} \mathrm{~kg}^{-1}$; total N: 6.7-8.7 $\mathrm{g} \mathrm{kg}^{-1} \mathrm{ds}$; Fig. 3) up to three months after the fire. However, one year later, the SOM content in US (total $\mathrm{C}$ and $\mathrm{N}$ ) was higher than in all the other treatments, the differences with BS+Ap (C and N) and with BS and BS+Fo (C) being significant.

In the first year after the fire, $\delta{ }^{15} \mathrm{~N}$ values for US rose from +1.45 to $+1.75 \delta$, with no clear temporal tendency. However, immediately after the prescribed fire, there was a decrease of 0.2$0.5 \delta{ }^{15} \mathrm{~N}$ in BS, BS+Fo, BS+Fi and BS+Ap in comparison with US, although the difference was only significative in the case of BS+Ap (Fig. 4). One month later, a slight decrease in BS remained, but $\delta{ }^{15} \mathrm{~N}$ in $\mathrm{BS}+\mathrm{Fo}, \mathrm{BS}+\mathrm{Fi}$ and $\mathrm{BS}+\mathrm{Ap}$ started to rise, especially in $\mathrm{BS}+\mathrm{Ap}$, the mean value of which did not differ from US; the same was true for BS, BS+Fo and BS+Fi at $t=90 \mathrm{~d}$. This tendency to rise was still evident after $365 \mathrm{~d}$, and all BS treatments reached values $(+2.22$ to +2.57 ס) significatively higher than US.

Compared with US, immediately after burning there was an increase in $\mathrm{NH}_{4}{ }^{+}-\mathrm{N}$ in all BS treatments, although differences were only significant in those with fire fighting chemicals. At $\mathrm{t}=1 \mathrm{~d}, \mathrm{NH}_{4}{ }^{+}-\mathrm{N}$ concentration increased in the order $\mathrm{US} \leq \mathrm{BS}<\mathrm{BS}+\mathrm{Fo}, \mathrm{BS}+\mathrm{Fi}<\mathrm{BS}+\mathrm{Ap}$, with the $\mathrm{NH}_{4}{ }^{+}-\mathrm{N}$ content in BS+Ap being 200 times higher than that in US, and 9-18 times higher than those in BS, BS+Fo, BS+Fi (Fig. 5). The post-fire increase of $\mathrm{NH}_{4}{ }^{+}-\mathrm{N}$ levels was transient in BS, $\mathrm{BS}+\mathrm{Fo}$ and $\mathrm{BS}+\mathrm{Fi}$, their values being similar to that of US at $\mathrm{t}=30 \mathrm{~d}$; conversely, in BS+Ap the $\mathrm{NH}_{4}{ }^{+}-\mathrm{N}$ content remained significantly higher than in the other treatments for at least three months, although differences were not significant at $t=365 \mathrm{~d}$.

Contrary to $\mathrm{NH}_{4}{ }^{+}-\mathrm{N}, \mathrm{NO}_{3}{ }^{-}-\mathrm{N}$ concentrations did not differ significantly among treatments at $\mathrm{t}=1 \mathrm{~d}$ (Fig. 5). The same was true one month later, except for $\mathrm{BS}+\mathrm{Ap}$, for which $\mathrm{NO}_{3}^{-}-\mathrm{N}$ content was higher $(P<0.05)$ than in the other treatments. Irrespective of soil treatment, at $\mathrm{t}=90 \mathrm{~d}$ there was a generalized increase of $\mathrm{NO}_{3}^{-}-\mathrm{N}$ content and, like at $\mathrm{t}=30 \mathrm{~d}$, maximum $\mathrm{NO}_{3}{ }^{-}-\mathrm{N}$ levels $(P<$ $0,05)$ were found in $\mathrm{BS}+\mathrm{Ap}$. At $\mathrm{t}=365 \mathrm{~d}, \mathrm{NO}_{3}^{-}-\mathrm{N}$ concentration was similar in all treatments and comparable to those data obtained before burning.

Available P content in BS was higher than in US, but the difference was not significative (Fig. 6). The same was true for the treatments with fire fighting chemicals, except for BS+Ap which showed a huge increase in soil available $\mathrm{P}\left(817 \mathrm{mg} \mathrm{P} \mathrm{kg}^{-1} \mathrm{ds}\right.$ at $\mathrm{t}=1 \mathrm{~d} ; 70-140$ times higher than the concentration in the other treatments; Fig. 6). Despite the sustained decrease in P levels throughout the entire study period, even after a year the BS+Ap values $\left(51.9 \mathrm{mg} \mathrm{P} \mathrm{kg}^{-1} \mathrm{ds}\right.$ ) were still significatively higher than those of the other treatments (10-20 times).

The concentration of available cations in the burnt plots, with or without fire fighting chemicals, was higher than in the unburnt plots up until $90 \mathrm{~d}$ after the prescribed fire, although differences were not always significative, except for K (Fig. 7). Monovalent cation concentrations decreased slowly during the first three months after the burning; conversely, after a transitory decrease at $\mathrm{t}=30 \mathrm{~d}$, and the divalent cation content at $\mathrm{t}=90 \mathrm{~d}$ increased to levels that were close to those measured immediately after burning.

\section{Discussion}

The significant increase of soil $\mathrm{pH}_{\mathrm{KCl}}$ observed after the prescribed fire was in all likelihood due to the accumulation of ashes rich in oxides and carbonates of basic ions and the reduction of organic acids that have been reported by several authors (Chandler et al., 1983; Kutiel et al., 
1990; Carballas, 1997). The additional increment of soil $\mathrm{pH}_{\mathrm{KCl}}$ in burnt soils treated with flame suppression chemicals could be due to the cations supplied by these chemicals, whose water solutions at the concentration used in fire-fighting have a neutral $\mathrm{pH}$ (foaming agent at $1 \% \mathrm{pH}$ 7.2; Firesorb at $1.5 \% \mathrm{pH} 7.0$; ammonium polyphosphate at $20 \% \mathrm{pH} 6.2$ ). Although initially (the first 3 months of warm and dry summer) the soil $\mathrm{pH}$ remained significantly higher in BS than in US, one year after the fire the burnt soil $\mathrm{pH}$ decreases to values close to US, following a common trend in burnt soils, which is mainly due to the leaching of basic ions during the wet season (Viro, 1974; Pritchett and Fisher, 1987); the same was true for the burnt soils treated with fire fighting chemicals, as was also found by Hopmans and Bickford (2003) in one of the two unburnt soils they treated with Phos-Check.

The lack of significant differences in SOM richness among the soil treatments up until three months after the fire showed that neither the prescribed fire nor the addition of fire fighting chemicals influenced the soil $\mathrm{C}$ and $\mathrm{N}$ content in the short term; similarly, no significant differences were found by Hopmans and Bickford (2003) in SOM content of unburnt soils treated with Phos-Check. On the other hand, the SOM depletion observed one year later in all treatments with burnt soil may be the medium-term consequence of the fire-triggered erosion processes on the surface of burnt plots .

The $\delta{ }^{15} \mathrm{~N}$ decrease in burnt soils just after the fire was without doubt due to the $\mathrm{N}$ added to the soil surface by the ashes from plant material (either living plants or litter), which were impossible to differentiate from the upper soil layer ashes and, consequently, jointly sampled. The natural abundance of ${ }^{15} \mathrm{~N}$ in the litter $(-1.1 \delta)$ showed that the leguminous plants (Ulex europaeus, Chamaespartium tridentatum) that dominated the plant community of the plots were also depleted in ${ }^{15} \mathrm{~N}$ (as is usual in plants that actively fix $\mathrm{N}_{2}$; Shearer and Kohl, 1993) and, therefore, the contribution of ashes from litter and living plants provoked the decrease in $\delta{ }^{15} \mathrm{~N}$ in the 0-2 cm soil layer. The increment in $\delta{ }^{15} \mathrm{~N}$ that was evident between three months (one month in BS+Ap) and one year after the prescribed fire in all burnt plots, compared with US, clearly suggests that the fire had a medium-term influence on $\mathrm{N}$ balance, promoting the outputs, and which was undoubtedly due to an increase in lixiviation of nitrates or in volatilization of ammonia, which are ${ }^{15} \mathrm{~N}$ depleted (Högberg et al., 1995).

The $\mathrm{NH}_{4}{ }^{+}-\mathrm{N}$ increase that takes place just after the fire in all burnt soil treatments is a common tendency of recently heated or burnt soils (DeBano et al., 1979; Chandler et al., 1983; Prieto-Fernández et al., 1993). As has previously been mentioned, differences in $\mathrm{NH}_{4}{ }^{+}-\mathrm{N}$ content compared with the US were significant for all soils treated with fire fighting chemicals, but the extremely high concentration of BS+Ap was very likely due to the $\mathrm{NH}_{4}^{+}-\mathrm{N}$ supplied by the ammonium polyphosphate. Similarly, in field experiments with unburnt soils, Hopmans and Bickford (2003) also observed that Phos-Check (which contains ammonium polyphosphates and sulphates) stimulates a three to ten-fold increment in available $\mathrm{N}$ over initial values in the $0-20$ $\mathrm{cm}$ soil layer. Contrary to the results of Hopmans and Bickford (2003), who found no significant differences between control and Phos-Check - treated soils after 2 months, in BS+Ap the $\mathrm{NH}_{4}{ }^{+} \mathrm{N}$ levels remained significantly higher than in the other treatments for at least 3 months. The very high $\mathrm{NH}_{4}{ }^{+}-\mathrm{N}$ levels in $\mathrm{BS}+\mathrm{Ap}$, and its relative persistence over time, are features of high ecological significance for the post-fire vegetation recovery, as seed germination and seedling establishment can be inhibited by $\mathrm{NH}_{4}{ }^{+}$toxicity (see Britto and Kronzucker, 2002). In fact, in a greenhouse experiment with a burnt soil that received ammonium polyphosphate at the same dose as in the field, the germination of Lolium multiflorum and Agrostis tenuis seeds was reduced by $86-100 \%$ compared with the control burnt soil, and seedling establishment was completely inhibited (data not shown). However, in the medium-term the $\mathrm{NH}_{4}{ }^{+} \mathrm{-}$ supplied by the ammonium polyphosphate could have a fertilizing effect.

The initial lack of significant differences among treatments in the $\mathrm{NO}_{3}-\mathrm{N}$ levels disappeared for $\mathrm{BS}+\mathrm{Ap}$ between one and three months after the prescribed fire due to the active nitrification 
of its large $\mathrm{NH}_{4}^{+}-\mathrm{N}$ pool, which is unquestionably the cause of the significant soil acidification observed in the BS+Ap plots during this period (see Fig. 2). On the other hand, the general increase in the $\mathrm{NO}_{3}-\mathrm{N}$ concentration recorded at $\mathrm{t}=90 \mathrm{~d}$ in all soil treatments reflected a rise in the nitrifier microorganism activity, which was favoured by the higher soil humidity during the autumn, the season in which this sampling was carried out.

The increment in available P in BS compared with US was probably due to the strong mineralizing effect of fire on organic P reported by Saá et al. (1993), although in our case differences did not reach significant levels (Fig. 6). No fire fighting chemical had any influence on available P except ammonium polyphosphate, which provoked an increment in soil P levels that remained significantly higher (10-20 times) than for the other treatments, even one year after the fire. This result is in accordance with that of Hopmans and Bickford (2003) who, subsequent to the application of Phos-Check, also found a noticeable increase in available P (6-60 times in the $0-20 \mathrm{~cm}$ soil layer), which also remained over control soil levels over the following year. The medium-term ( $\geq 1$ year) persistence of high $P$ levels may acquire great importance for the post-fire vegetation recovery as: a) at high levels, $\mathrm{P}$ could have an antagonistic effect on $\mathrm{Fe}$ and Zn plant uptake (Marschner, 1995); and b) P is a common limiting nutrient. Moreover, the enhanced nutrient losses due to leaching and erosion that have habitually been reported in soils affected by wildfires (Chandler et al., 1983; Carballas et al., 1993) may increase risks of water eutrophication due to higher soil P outputs from the burnt soils treated with P-rich fire fighting chemicals.

The fire-induced increase of available cations observed in the burnt plots were in accordance with the results of DeBano et al. (1979) and Trabaud (1983) with burnt soils, and also with those of Fassbender (1975) for $\mathrm{Ca}, \mathrm{Mg}$ and $\mathrm{Na}$ in oven-heated soils. This effect is probably due to the accumulation of ashes rich in oxides and carbonates of basic ions that have been reported by several authors (Chandler et al., 1983; Kutiel et al., 1990; Carballas, 1997), and also to the cations (especially $\mathrm{Na}$ ) supplied by the fire fighting chemicals. While in all treatments divalent cation concentrations did not follow a clear temporal trend, due perhaps to seasonal changes in their availability, those of the monovalent cations decreased slowly during the first three months after the burning, which, in all probatility, was due to the greater solubility and propensity to leaching of the latter (Duchaufour, 1987).

\section{Conclusions}

Main consequences of soil burning are a transient (until 30-90 d) increase in $\mathrm{pH}$ and, not always significatively, in available nutrients (exchangeable $\mathrm{NH}_{4}{ }^{+}$, available $\mathrm{P}, \mathrm{Na}, \mathrm{K}, \mathrm{Mg}$ and Ca). The prescribed fire also provoked an initial decrease in soil $\delta{ }^{15} \mathrm{~N}$ followed by a steady increase, which, together with a medium-term (from 90 to $365 \mathrm{~d}$ ) reduction in SOM content, suggest a fire-triggered increment of soil erosion and $\mathrm{N}$ outputs $\left({ }^{15} \mathrm{~N}\right.$ depleted).

The transient effects of prescribed fire on soil $\mathrm{pH}$, exchangeable $\mathrm{NH}_{4}{ }^{+}$and $\delta{ }^{15} \mathrm{~N}$ were increased by the three fire fighting chemicals (slightly by foaming agent and Firesorb and more strongly by ammonium polyphosphate), whereas only the ammonium polyphosphate had effects on available P. The foaming agent increased the effects of fire on all available cations, whereas the addition of Firesorb only affected the Na and, to a lesser extent, Ca contents, and the application of ammonium polyphosphate only had minor effects on $\mathrm{Mg}$ levels. The extremely high initial levels of $\mathrm{NH}_{4}{ }^{+}-\mathrm{N}$ and available $\mathrm{P}$ in BS+Ap can delay the post-fire recovery of vegetation due to the toxicity of $\mathrm{NH}_{4}{ }^{+}$to seeds and seedlings and the antagonistic effect of $\mathrm{P}$ on Fe and $\mathrm{Zn}$ plant uptake. However, in the medium-term the $\mathrm{NH}_{4}{ }^{+}-\mathrm{N}$ and available $\mathrm{P}$ supplied by the ammonium polyphosphate could have a fertilizing effect on vegetation growth. The enhanced nutrient losses due to leaching and erosion that are usually reported in soils affected 
by wildfires may increase risks of water eutrophication due to higher soil $\mathrm{N}$ and P outputs from the burnt soils treated with N- and P-rich fire fighting chemicals.

\section{Acknowledgements}

We thank José Salmonte, Angela Martín, Ramón Tobar and Nélida Leite for technical assistance in the laboratory. This research was supported by the Spanish Ministery of Education and Science through the project number AGL2001-1242-C04-01. The participation of A. Couto in this research was supported by a CSIC-Xunta de Galicia fellowship. The isotopic ratio mass spectrometer was partly financed by the European Regional Development Fund (EU).

\section{REFERENCES}

Adams R, Simmons D. Ecological effects of fire fighting foams and retardants: a summary. Aust Forest 1999; 62: 307-314.

Aranibar JN, Macko SA, Anderson I, Potgieter ALF, Sowry R, Shugart HH. Nutrient cycling responses to fire frequency in the Kruger National Park (South Africa) as indicated by stable isotope analysis. Isot Environ Healt S 2003; 39: 141-158.

Basanta MR, Díaz-Raviña M, González-Prieto SJ, Carballas T. Biochemical properties of forest soils as affected by a fire retardant. Biol Fert Soils 2002; 36: 377-383.

Bell T, Tolhurst K, Wouters M. Effects of the fire retardant Phos-Chek on vegetation in eastern Australian heathlands. Int J Wildland Fire 2005; 14: 199-211.

Bradstock R, Sanders J, Tegart A. Short-term effects on the foliage of a eucalypt forest after an aerial application of a chemical fire retardant. Aust Forest 1987; 50: 71-80.

Britto DT, Kronzucker HJ. $\mathrm{NH}_{4}{ }^{+}$toxicity in higher plants: a critical review. J Plant Physiol 2002; 159: 567-584.

Carballas T. Effects of fires on soil quality. Biochemical aspects. In: Balabanis P, Eftichidis G, Fantechi R, editors. Forest fire risk and management. European Commission, Brussels, Belgium, 1997, pp. 249-261.

Carballas M, Acea MJ, Cabaneiro A, Trasar C, Villar MC, Díaz-Raviña M, Fernández I, Prieto A, Saá A, Vázquez J, Zehner R, Carballas, T. Organic matter, nitrogen, phosphorus and microbial population evolution in forest humiferous acid soils after wildfires. In: Trabaud L, Prodon R, editors. Fire in Mediterranean ecosystems. Ecosystems Research Series, Report 5. European Commission, Brussels, Belgium, 1993, pp. 379-385.

Chandler C, Cheney P, Thomas P, Trabaud L, Williams D. Fire in forestry, vol. I. Forest fire behavior and effects. Wiley, New York, 1983, 450 pp.

Cook GD. Effects of frequent fires and grazing on stable nitrogen isotope ratios of vegetation in northern Australia. Austral Ecol 2001; 26: 630-636.

DeBano LF, Eberlein GE, Dunn PH. Effects of burning on chaparral soils. I. Soil nitrogen. Soil Sci Soc Am J 1979; 43: 504-509.

Duchaufour P. Manual de Edafología. Ed. Masson, Barcelona, 1987, 214 pp. 
Fassbender HW. Experimentos de laboratorio para el estudio del efecto del fuego de la quema de restos vegetales sobre las propiedades del suelo. Turrialba 1975; 25: 249-254.

Gaikowski MP, Hamilton SJ, Buhl KJ, McDonald SF, Summers C. Acute toxicity of three fireretardant and two fire-suppressant foam formulations to the early life stages of Rainbow Trout (Oncorynchus mykiss). Environ Toxicol Chem 1996; 15: 1365-1374.

Garten CT. Variation in foliar ${ }^{15} \mathrm{~N}$ abundance and the availability of soil nitrogen on Walker Branch watershed. Ecology 1993; 74: 2098-2113.

Garten CT, Van Miegroet, H. Relationships between soil nitrogen dynamics and natural 15N abundance in plant foliage from Great Smoky Mountains National Park. Can J Forest Res 1994; 24: $1636-1645$.

George CW, Blakely AD, Johnson GM. Forest fire retardant research - a status report. USDA. Forest Service Research Paper, Intermountain Forest and Range Experiment Station, General Technical Report INT-31 (Ogden, UT), 1976.

Giménez A, Pastor E, Zarate L, Planas E, Arnaldos J. Long-term forest fire retardants: a review of quality, effectiveness, application and environmental. Int J Wildland Fire 2004; 13: 1-15.

Hartskeerl K, Simmons D, Adams R. Does firefighting foam affect the growth of some Australian native plants? Int J Wildland Fire 2004; 13: 335-341.

Högberg P. Development of ${ }^{15} \mathrm{~N}$ enrichment in a nitrogen-fertilised forest soil-plant system. Soil Biol Biochem 1991; 23: 335-338.

Högberg P, Johannisson C. ${ }^{15} \mathrm{~N}$ abundance of forests is correlated with losses of nitrogen. Plant Soil 1993; 157: 147-150.

Högberg P, Johannisson C, Högberg M, Högbom L, Näsholm T, Hällgren JE. Measurements of abundances of ${ }^{15} \mathrm{~N}$ and ${ }^{13} \mathrm{C}$ as tools in retrospective studies of $\mathrm{N}$ balances and water stress in forests: A discussion of preliminary results. Plant Soil 1995; 168-169: 125-133.

Hopmans P, Bickford R. Effects of fire retardants on heathland soils in Victoria. Fire Management Department of Sustainability and Environment, Victoria, Australia. Research Report no 70, 2003, 23 pp.

Koba K, Hirobe M, Koyama L, Kohzu A, Tokuchi N, Nadelhoffer KJ, Wada E, Takeda H. Natural $\mathrm{N}-15$ abundance of plants and soil $\mathrm{N}$ in a temperate coniferous forest. Ecosystems 2003; 6: 457-469.

Kutiel P, Naveh Z, Kutiel H. The effects of a wildfire on soil nutrients and vegetation in an Aleppo pine forest on Mount Carmel, Israel. In: Goldammer JG, Jenkins MJ, editors. Fire in ecosystem dynamics, Mediterranean and Northern Perspectives. SPB Academic Publishing, The Hague, The Netherlands, 1990, pp. 85-94.

Larson JR, Duncan DA. Annual grassland response to fire retardant and wildfire. J Range Manage 1982; 35: 700-703.

Larson DL, Newton WE, Anderson PJ, Stein SJ. Effects of fire retardant chemical and fire suppressant foam on shrub steppe vegetation in northern Nevada. Int J Wildland Fire 2000; 9: 115-127.

Marschner H. Mineral nutrition of higher plants. 2nd Ed. Academic Press, New York, 1995, 889 
pp.

McDonald SF, Hamilton SJ, Buhl KJ, Heisinger JF. Acute toxicity of fire control chemicals to Daphnia magna (Straus) and Selenastrum capricornutum (Printz). Ecotox Environ Safe 1996; 33: 6272.

McDonald SF, Hamilton SJ, Buhl KJ, Heisinger JF. Acute toxicity of fire-retardant and foamsuppressant chemicals to Hyalella azteca (Saussure). Environ Toxicol Chem 1997; 16: 1370-1376.

Neary DG, Currier JB. Impact of wildfire and watershed restoration on water quality in South Carolina's Blue Ridge Mountains. South J For 1982; 6: 81-90.

Pritchett WL, Fisher RF. Properties and Management of Forest Soils. Wiley. New York, NY, 1987, 494 pp.

Prieto-Fernández A, Villar MC, Carballas M, Carballas T. Short-term effects of a wildfire on the nitrogen status and its mineralization kinetics in an Atlantic forest soil. Soil Biol Biochem 1993; 25: 1657-1664.

Robinson D. Delta N-15 as an integrator of the nitrogen cycle. Trends Ecol Evol 2001;16:153-162.

Saá A, Trasar-Cepeda C, Gil-Sotres F, Carballas T. Changes in soil phosphorous and acid phosphatase activity inmediately following forest fires. Soil Biol Biochem 1993; 25: 1223-1230.

Shearer G, Kohl DH. Natural abundance of ${ }^{15} \mathrm{~N}$. In: Knowles R, Blackburn TH, editors. Nitrogen isotope techniques. Academic Press, San Diego, CA, 1993, pp. 89-125.

SchmidtS, Stewart GR. Delta N-15 values of tropical savanna and monsoon forest species reflect root specialisations and soil nitrogen status. Oecologia 2003; 134: 569-577.

Trabaud L. The effects of different fire regimes on soil nutrients levels in Quercus coccifera garrigue. In: Kruger TJ , Mitchel DT, Harvis TUM, editors. Mediterranean type ecosystems. The role of nutrients. Ecological Studies 43. Springer-Verlag, Berlin, 1983, pp. 233-243.

Viro PJ. Effects of forest fire on soil. In: Kozlowski TT, Ahlgren CE, editors. Fire and ecosystems. Academic Press, London, 1974, pp. 7-46. 
Table 1. Density, total nutrient content and $\delta^{15} \mathrm{~N}$ (mean \pm s.d.; $\mathrm{n}=3$ ) in the three fire fighting chemicals used.

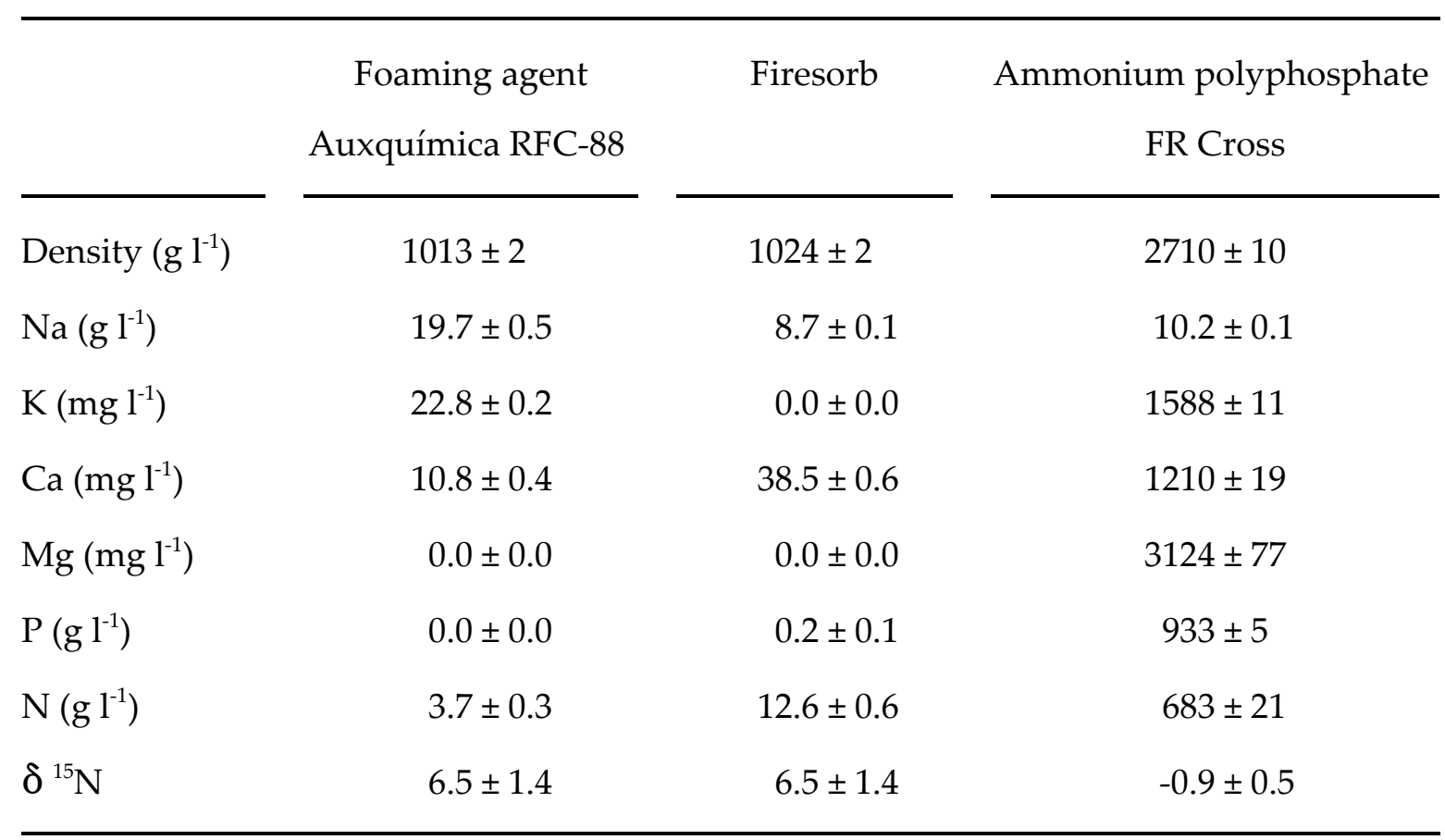




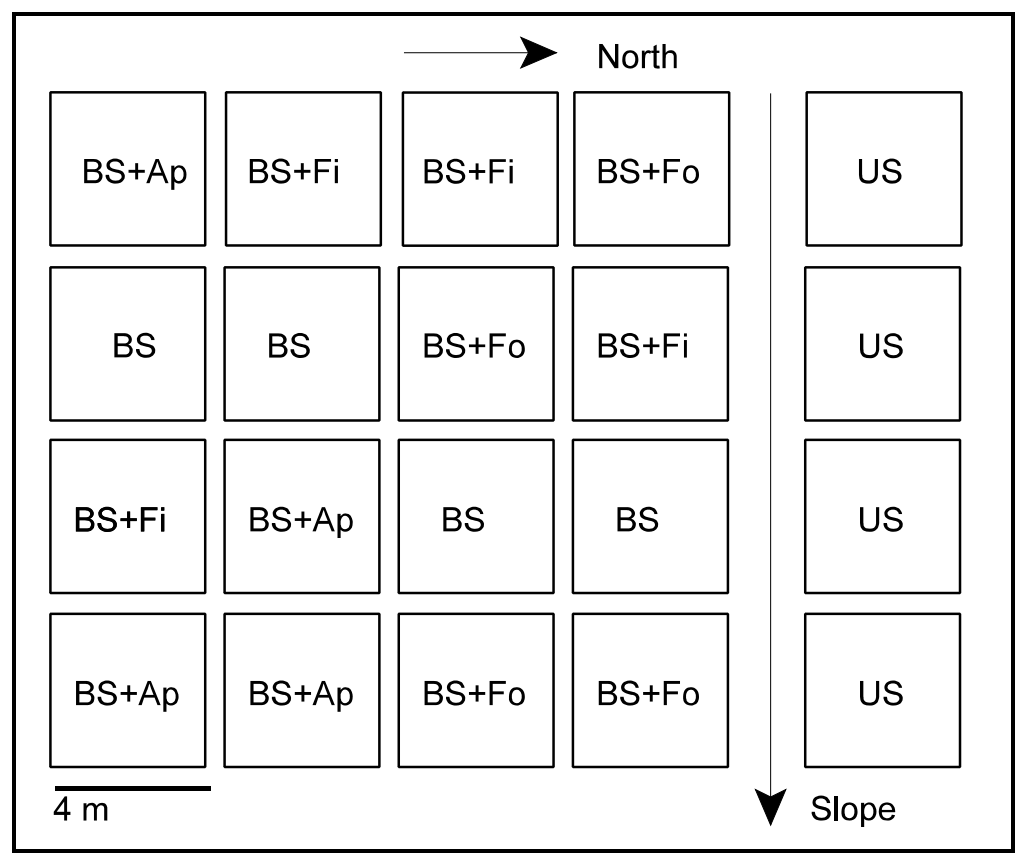

Fig. 1. Plot distribution on the study area. Key: US, unburnt soil; BS, burnt soil; BS+Fo, burnt soil + foam agent; BS+Fi, burnt soil + Firesorb; BS+Ap, burnt soil + ammonium polyphosphate. 


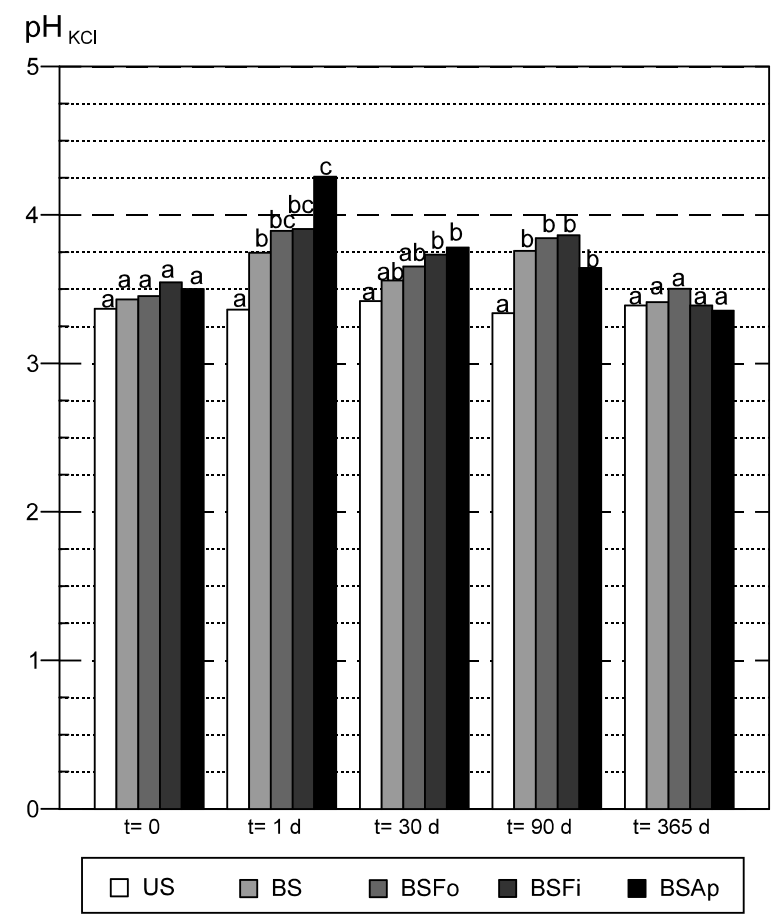

Fig. 2. Evolution of $\mathrm{pH}$ in the 0-2 $\mathrm{cm}$ soil layer along a year after the prescribed fire. Key: US, unburnt soil; BS, burnt soil; BS+Fo, burnt soil + foam agent; BS+Fi, burnt soil + Firesorb; BS+Ap, burnt soil + ammonium polyphosphate. At each sampling date, different letters (a, $b, c, \ldots)$ indicate significant differences $(\mathrm{P}<0.05)$. 

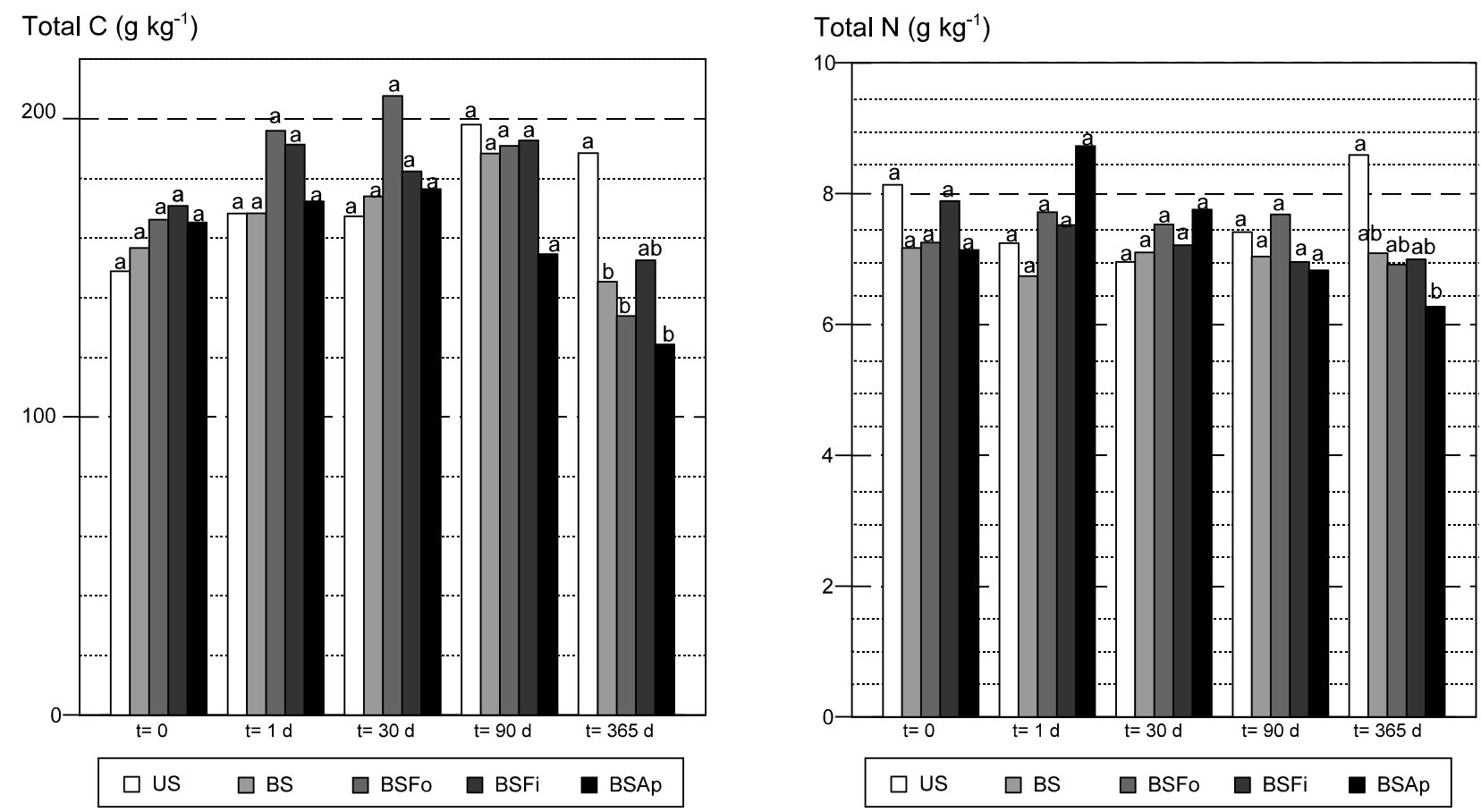

Fig. 3. Evolution of $\mathrm{C}$ and $\mathrm{N}$ content in the $0-2 \mathrm{~cm}$ soil layer along a year after the prescribed fire. Key: US, unburnt soil; BS, burnt soil; BS+Fo, burnt soil + foam agent; BS+Fi, burnt soil + Firesorb; BS+Ap, burnt soil + ammonium polyphosphate. At each sampling date, different letters $(a, b, c, \ldots)$ indicate significant differences $(P<0.05)$. 


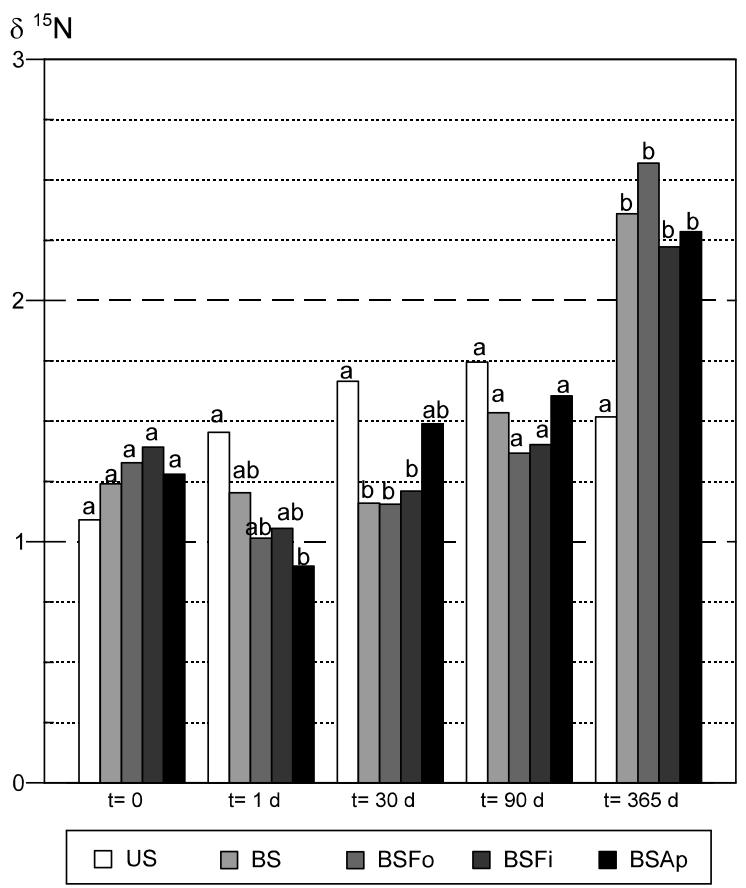

Fig. 4. Evolution of $\delta{ }^{15} \mathrm{~N}$ in the $0-2 \mathrm{~cm}$ soil layer along a year after the prescribed fire. Key: US, unburnt soil; BS, burnt soil; BS+Fo, burnt soil + foam agent; BS+Fi, burnt soil + Firesorb; BS+Ap, burnt soil + ammonium polyphosphate. At each sampling date, different letters (a, $b, c, \ldots)$ indicate significant differences $(P<0.05)$. 


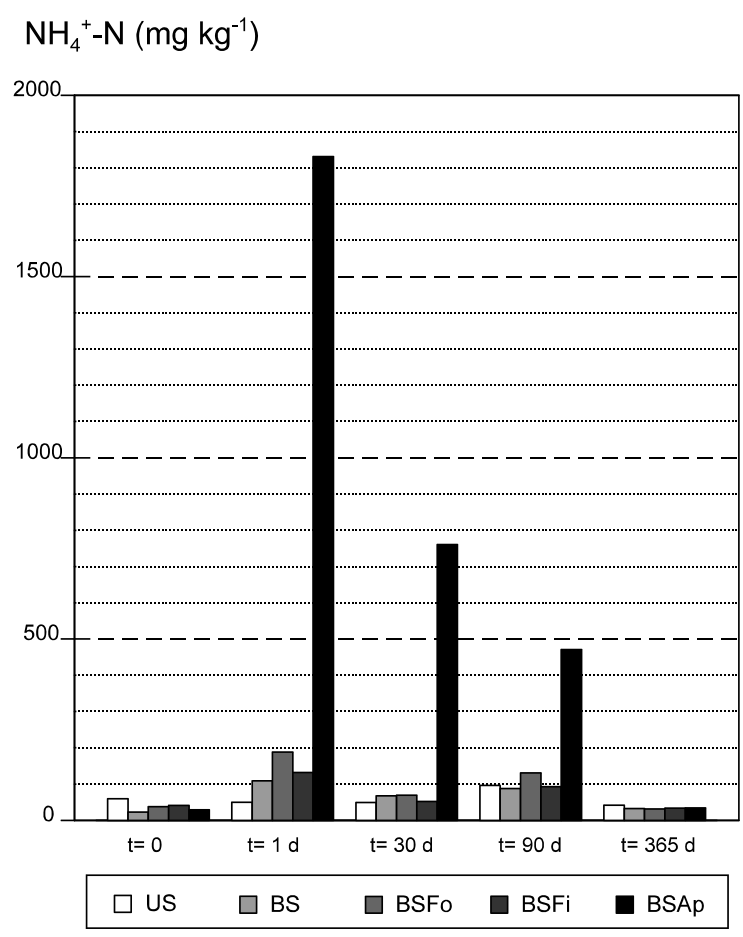

$\mathrm{NO}_{3}^{-}-\mathrm{N}\left(\mathrm{mg} \mathrm{kg}^{-1}\right)$

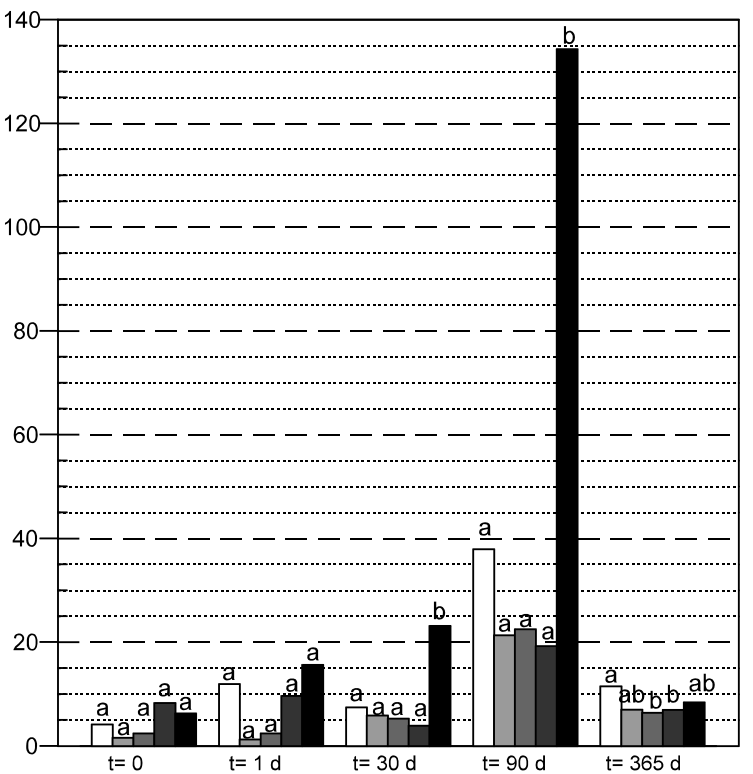

Fig. 5. Evolution of $\mathrm{NH}_{4}{ }^{+} \mathrm{N}$ and $\mathrm{NO}_{3}-\mathrm{N}$ content in the $0-2 \mathrm{~cm}$ soil layer along a year after the prescribed fire. Key: US, unburnt soil; BS, burnt soil; BS+Fo, burnt soil + foam agent; BS+Fi, burnt soil + Firesorb; BS+Ap, burnt soil + ammonium polyphosphate. At each sampling date, different letters $(a, b, c, \ldots)$ indicate significant differences $(P<0.05)$. 


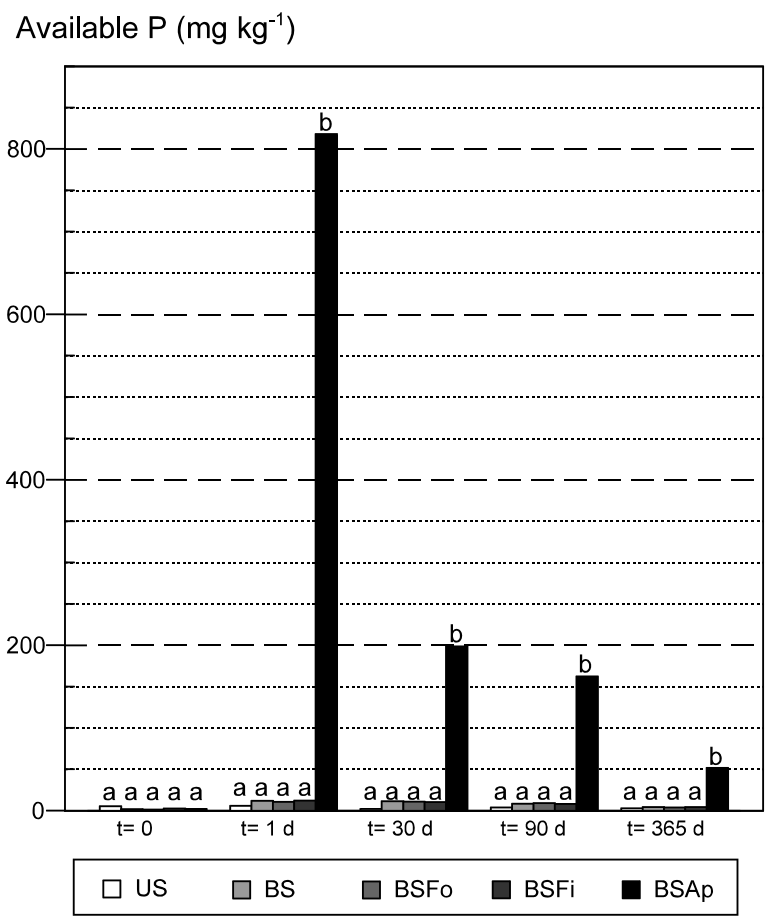

Fig. 6. Evolution of available $\mathrm{P}$ content in the $0-2 \mathrm{~cm}$ soil layer along a year after the prescribed fire. Key: US, unburnt soil; BS, burnt soil; BS+Fo, burnt soil + foam agent; BS+Fi, burnt soil + Firesorb; BS+Ap, burnt soil + ammonium polyphosphate. At each sampling date, different letters $(a, b, c, \ldots)$ indicate significant differences $(P<0.05)$. 
Available $\mathrm{Na}\left(\mathrm{mg} \mathrm{kg}^{-1}\right)$

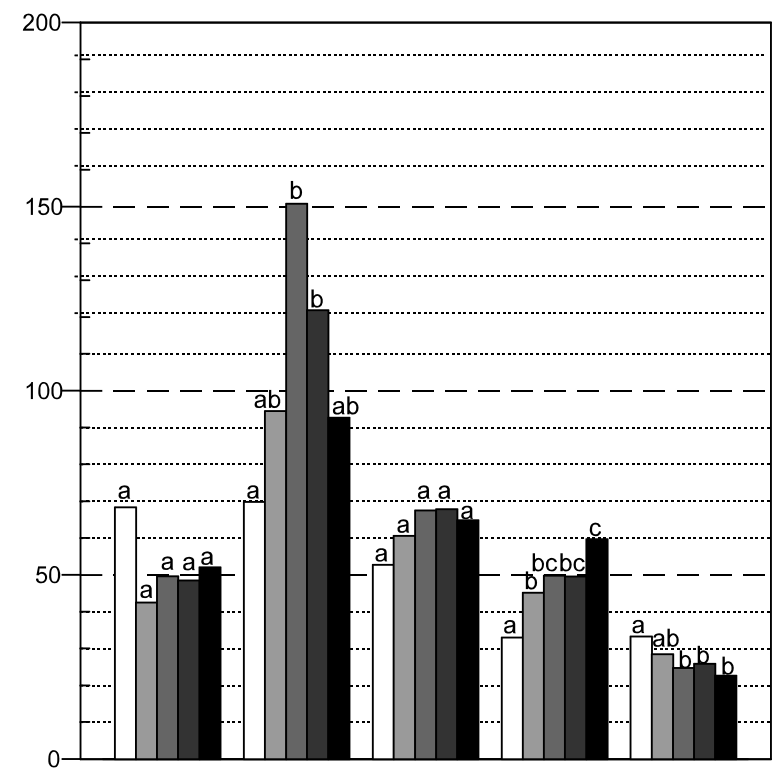

Available $\mathrm{Mg}\left(\mathrm{mg} \mathrm{kg}^{-1}\right)$

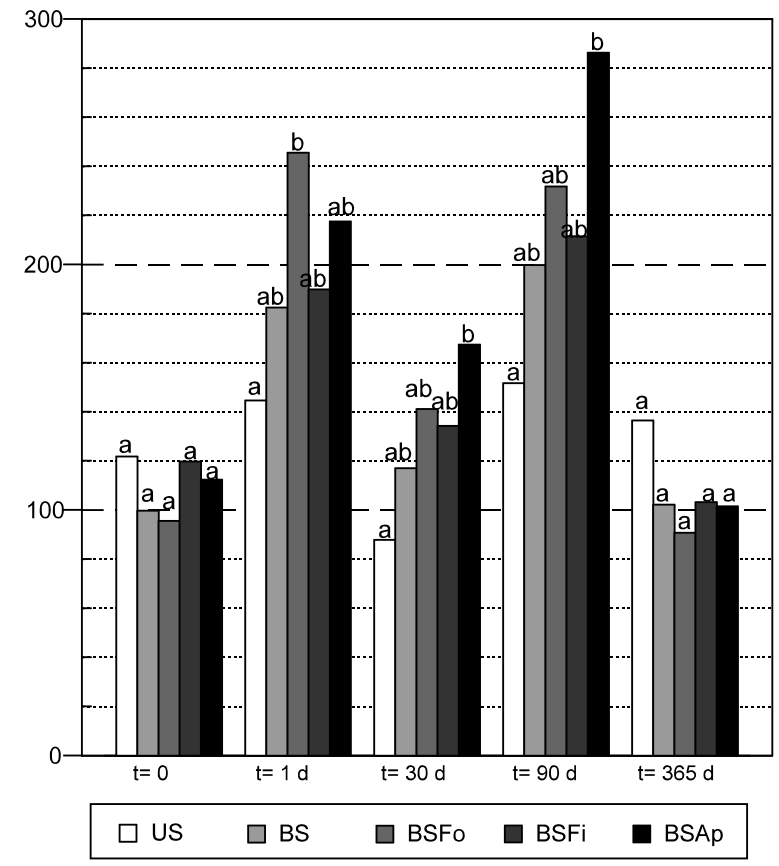

Available $\mathrm{K}\left(\mathrm{mg} \mathrm{kg}^{-1}\right)$

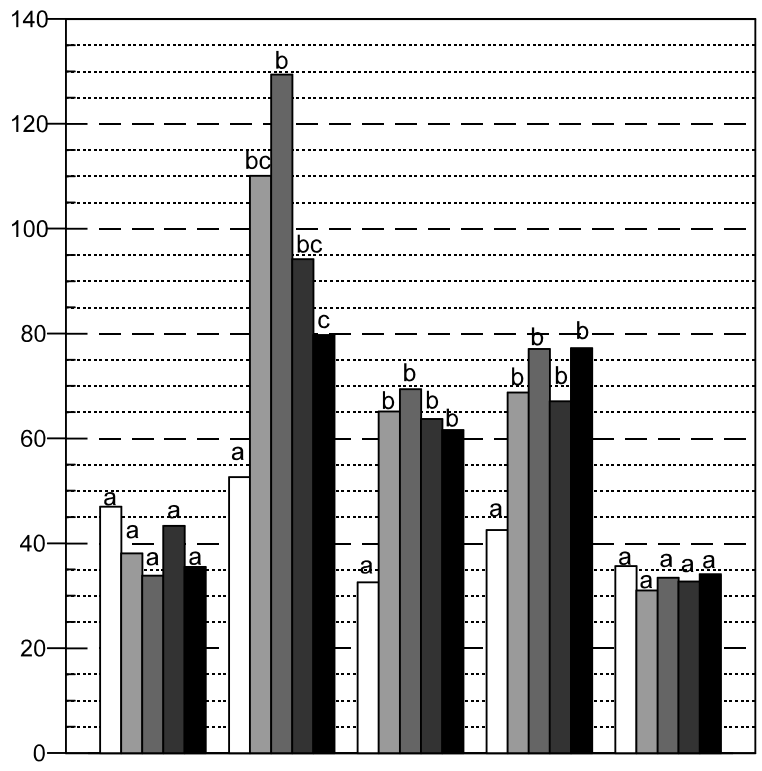

Available $\mathrm{Ca}\left(\mathrm{mg} \mathrm{kg}^{-1}\right)$

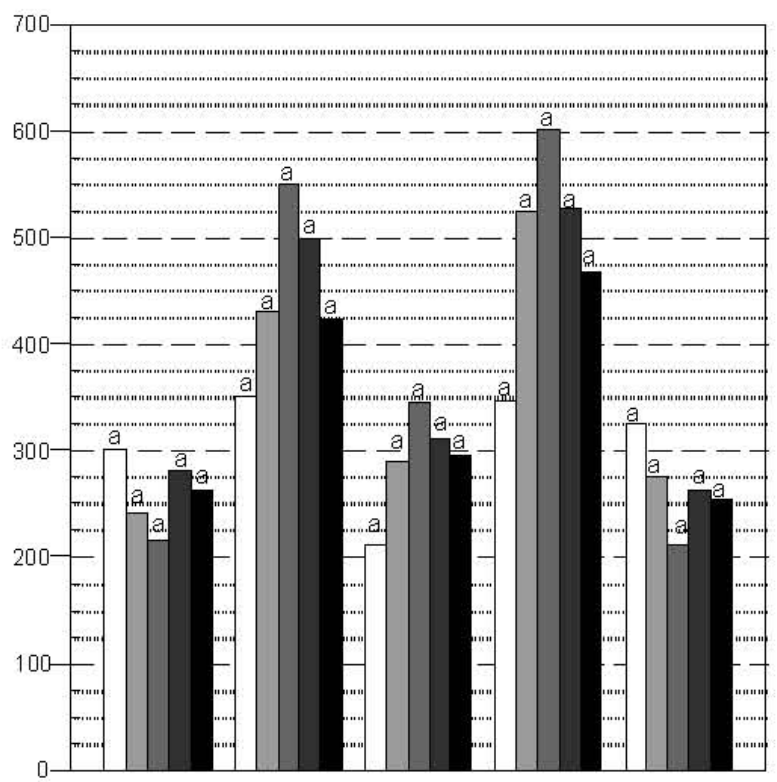

Fig. 7. Evolution of available $\mathrm{Na}, \mathrm{K}, \mathrm{Mg}$ and $\mathrm{Ca}$ content in the $0-2 \mathrm{~cm}$ soil layer along a year after the prescribed fire. Key: US, unburnt soil; BS, burnt soil; BS+Fo, burnt soil + foam agent; BS+Fi, burnt soil + Firesorb; BS+Ap, burnt soil + ammonium polyphosphate. At each sampling date, different letters $(a, b, c, \ldots)$ indicate significant differences $(\mathrm{P}<0.05)$. 